\title{
Lateral glances toward moving stimuli among young children with autism: Early regulation of locally oriented perception?
}

\author{
LAURENT MOTTRON,${ }^{a}$ SUZANNE MINEAU,${ }^{a}$ GENEVIÈVE MARTEL,${ }^{a}$ \\ CATHERINE ST-CHARLES BERNIER, ${ }^{a}$ CLAUDE BERTHIAUME ${ }^{a}$ \\ MICHELLE DAWSON,${ }^{a}$ MICHEL LEMAY, ${ }^{a}$ SYLVAIN PALARDY, ${ }^{a}$ \\ TONY CHARMAN, ${ }^{b}$ AND JOCELYN FAUBERT ${ }^{a}$ \\ ${ }^{a}$ University of Montréal; and ${ }^{b}$ University College London
}

\begin{abstract}
Autistic adults display enhanced and locally oriented low-level perception of static visual information, but diminished perception of some types of movement. The identification of potential precursors, such as atypical perceptual processing, among very young children would be an initial step toward understanding the development of these phenomena. The purpose of this study was to provide an initial measure and interpretation of atypical visual exploratory behaviors toward inanimate objects (AVEBIOs) among young children with autism. A coding system for AVEBIOs was constructed from a corpus of 40 semistandardized assessments of autistic children. The most frequent atypical visual behavior among 15 children aged 33-73 months was lateral glance that was mostly oriented toward moving stimuli and was detected reliably by the experimenters (intraclass correlation $>.90$ ). This behavior was more common among autistic than typically developing children of similar verbal mental age and chronological age. As lateral vision is associated with the filtering of high spatial frequency (detail perception) information and the facilitation of high temporal frequencies (movement perception), its high prevalence among very young autistic children may reflect early attempts to regulate and/or optimize both excessive amounts of local information and diminished perception of movement. These findings are initial evidence for the need to consider the neural bases and development of atypical behaviors and their implications for intervention strategies.
\end{abstract}

These behaviors are very important to me: I did them a lot and mostly in secret, and still have themenjoy them. For years as a child (6-11 years or so) I spent hours with shampoo bottles moving them to make the air bubbles move up and down. I did this locked in the bathroom whenever I thought nobody would notice. Also, regarding movement, I had bad problems "seeing" big things, like furniture, rooms, etc. To see them, I would gallop by (like a horse, not like a human runner) with my head cocked. The objects would not move so I did. When I am tired I always cock my head to try to recognize things and look through my fingers. (Michelle Dawson, personal communication)

Address correspondence and reprint requests to: Laurent Mottron, Hôpital Rivière-des-Prairies, 7070 Boulevard Perras, Montréal, Quebec H1E 1A4, Canada; E-mail: mottronl@istar.ca.
Autistic adults appear to process static local elements of visual information more independently from their visual context than comparison individuals (Mottron, Burack, Iarocci, Belleville, \& Enns, 2003; O'Riordan, Plaisted, Driver, \& Baron-Cohen, 2001; Plaisted, O'Riordan, \& Baron-Cohen, 1998a; Shah \& Frith, 1983, 1993; see Dakin \& Frith, 2005, for a review). They also discriminate elementary dimensions and features at a superior level (Bertone, Mottron, Jelenic, \& Faubert, 2005; Plaisted, O'Riordan, \& Baron-Cohen, 1998b). In contrast, with enhanced perception of static targets and dimensions (Mottron, Dawson, Soulières, Hubert, \& Burack, 2006), movement perception is generally diminished or impaired (Bertone, Mottron, Jelenic, \& Faubert, 2003; Milne, Swettenham, \& Campbell, 
2005; for a review: Pellicano, Gibson, Maybery, Durkin, \& Badcock, 2005). Although a content-specific impairment for social stimuli, such as human faces, has commonly been invoked as a core-processing impairment in autism, the hypothesis that perturbations in the perceptual processing of any type of material are implicated in atypical behavior toward faces is gaining increasing support. More specifically, enhanced perception of local aspects (Lahaie et al., 2006) and increased use of high spatial frequencies (Boeschoten, Kemner, Kenemans, \& Engeland, 2005; Deruelle, Rondan, Gepner, \& Tardif, 2004) has also been demonstrated for social stimuli, and superior processing for low-level visual dimensions (Bertone et al., 2005) has been proposed as one reason for atypical attention toward faces in children and adults with autism (Lahaie et al., 2006). However, most knowledge about atypical visual information processing has been obtained through studies with high functioning adolescent or adult individuals, and therefore, is not yet empirically related to atypical visual behavior evident in autistic children at the beginning of their development.

The notion that autistic children present atypical visual behavior toward social information, like faces, and atypical attention toward objects attended by caregivers is one of the most documented abnormalities evident in young children with autism (e.g., Chawarska, Klin, \& Volkmar, 2003, for a recent review). Most of these behaviors may be classified under the category of "negative symptoms" of autism, in the sense that they are composed of behaviors or performance evident in typical children, but absent in autistic children. However, atypical visual exploratory behaviors for inanimate objects (AVEBIOs) in early development have, dating back to early autism research, also been observed (Kanner, 1943; Ritvo et al., 1969; Ritvo \& Laxer, 1983; Ritvo, Ornitz, \& La Fanchi, 1968), and are integrated in the clinical knowledge of autism. In their early diagnostic instrument, Freeman, Ritvo, Yokota, and Ritvo (1986) included "watch motion hand-object, lines up objects, visual detail scrutiny." The consensual update on screening and diagnostic practices in autism
(Filipek et al., 1999, p. 446) indicates that "some children will often look at objects out of the corner of their eyes." Ritvo et al. (1986) reported a "preferential use of peripheral fields" and "spinning and flapping objects in peripheral fields." The Autism Diagnostic Observation Schedule - Generic (ADOS-G; Lord et al., 2000) and the Autism Diagnostic InterviewRevised (ADI-R; Lord, Rutter, \& Le Couteur, 1994) include items such as "peering at an object while tilting his head and jiggling his hands" and "looking out of the corner of the eyes" (ADOS-G), "hand mannerisms, as moving fingers in front of the eyes, associated with distress when interrupted," "rapid, voluntary, repetitious movements of the fingers and hands, often within the line of the subject's vision," "unusual sensory interests, as peering at or look at things for long periods of time," and "interests in parts of objects (e.g., spinning the wheels of a car or opening and shutting its door), rather than using it as it was intended" (ADI-R). All these particularities are "positive" symptoms of autism in that they are absent in typical children and observed only in autistic children.

Empirical studies of AVEBIOs are scarce (O’Neill \& Jones, 1997). Although early studies suspected a relation between repetitive movements and periodic (flickering) stimulation (Colman, Frankel, Ritvo, \& Freeman, 1976; Frankel, Freeman, Ritvo, Chikami, \& Carr, 1976), most recent studies are focused on the specificity to autism of repetitive behaviors and their ability to discriminate autistic from nonautistic neurodevelopmental disorders. One study using parental responses to standardized questions found a significantly higher occurrence of "repetitive use of objects," "unusual sensory behaviors," and "hand and finger mannerisms" in a group of autistic children than in a group of mentally retarded and/or language delayed nonautistic children (Lord, Storoschuck, Rutter, \& Pickles, 1993). Using the same procedure, the second and third of these behaviors were able to distinguish autistic from nonautistic children at age 2 (Lord, 1995). Another study using home videos (Baranek, 1999) looked at two object stereotypies, twiddle/wave and visual staring/fixation. Scoring was based on behav- 
iors in natural settings. Unexpectedly, the author found fewer object fixations in the autistic group.

The latter negative finding can be explained by AVEBIOs being merged into various kinds of repetitive behaviors (twiddle, tap, spin, line up, rub, mouthing objects) as well as by parental reluctance to film "strange" behaviors. AVEBIOs may also be merged into "sensory symptoms," and therefore poorly characterized. The use of parental questionnaires, even validated ones such as the Short Sensory Profile (Dunn, 1999), which is supposed to detect low-frequency behaviors that are missed by direct observation, actually limits severely the precision of reported information (Rogers, Hepburn, \& Wehner, 2003). When the ADI-R is used as a measure of AVEBIOs, the visuoperceptive component of these behaviors is merged with a miscellany of repetitive behaviors involving other perceptual modalities, or not associated with perception. Moreover, the wording of ADI-R questions and ADOS-G coding does not allow documentation of the physical properties of objects associated with AVEBIOs.

Gaining more detailed empirical information about AVEBIOs in autism is important for several reasons. First, to demonstrate that AVEBIOs may be theoretically relevant, one must ensure that these behaviors are not a mere extension of what is observed in typical children of similar or younger developmental age. Second, precise characterization of early spontaneous visual behaviors may help in interpreting their mechanism and function, in relation to what is known of typical visual perception and of visual perception of static and moving objects in autistic adults. Third, the demonstration that early processing of visual information is atypical in autism, whatever type of material is processed, may allow discrimination between models emphasizing the predominance of a social impairment in autism (Dawson, Webb, \& McPartland, 2005; e.g., Schultz, 2005; Sigman, Dijamco, Gratier, \& Rozga, 2004) versus those emphasizing atypical information processing per se (Dakin \& Frith, 2005; Frith, 2003; Minshew, Goldstein, \& Siegel, 1997; Mottron et al., 2006; Plaisted, 2001). Fourth, possible future studies on the specificity of these behaviors to autism (in comparison to other neurodevelopmental disorders) will be dependent on a preliminary finegrained characterization of these AVEBIOs.

Our purpose in the present study was to develop an instrument that detects, describes, and assesses AVEBIOs with sufficient precision and reliability; to characterize the relative frequency of AVEBIOs; to document their specificity compared to typical development; and to provide a testable model of these behaviors resulting from this characterization. A coding system for the detection of most frequent AVEBIOs was therefore constructed. The reliability of this instrument was then tested. The specificity of the most frequent AVEBIOs (lateral glances) to autism versus typical development was investigated through a comparison of its frequency and duration in typical children and autistic children of similar chronological and verbal mental age (VMA). The correlation of the most frequent AVEBIOs (lateral glances) with developmental age, chronological age (CA), and ADOS-G scores was also examined. The behavioral sequences and contexts of lateral glances were analyzed, to determine how they cluster in a single individual and which physical properties of surrounding objects may trigger them. Then, an interpretation of lateral glance consistent with what is known of adult autistic visual perception and of the perceptual consequences of lateral glance in typical adults was provided.

\section{Study 1: Constructing a Reliable Instrument for Measuring AVEBIOs}

\section{Coding system construction}

The first step of coding system construction consisted of establishing a list of all possible AVEBIOs: (a) using a source that does not "filter" these behaviors, as home movies and "sensory" instruments are suspected to do; (b) without being influenced by the previous literature; (c) at whatever frequency these behaviors occur in ecological settings; (d) in a sufficiently rich situation to maximize the chances of the samples containing AVEBIOs; (e) using a "biased" sample, that is, in a cor- 
pus selected on the basis of frequency of AVEBIOs; and (f) in a setting standardized enough to allow further comparison of AVEBIOs frequency among autistic and typically developing groups.

A "biased" sample of 40 videos of ADOS-G assessments performed by, or under the supervision of, one of the authors (S.M.) was selected out of 300 ADOS-G modules 1 and 2 on the basis of the intensity and frequency of AVEBIOs, as reported in file information. All children were positive for an ADOS-G diagnosis of autism. This resulted in a sample enriched in AVEBIOs, allowing us to provide an estimation of the relative frequency of each behavior, and therefore to select behaviors sufficiently frequent to allow reliability procedures.

The 40 videos were randomly divided into a series of 32 videos used for establishing the behavior coding system, and 8 videos used for frequency estimation. Using two different samples for behavioral inventory and for frequency estimation diminished the biases because of the incidental properties of a specific sample. The larger number of videos, in addition to the fact that a "biased" sample was used, was considered to be required to discern atypical behaviors in the absence of a priori knowledge of these behaviors. The risk of using a too small number of videos to assess for AVEBIOs frequency was compensated for by an additional verification of frequency in the corpus used in Study 2. A first list of AVEBIOs was established by a rater naïve to autism, from the first subgroup of 32 of these assessments ( 28 boys, 4 girls, CA: $M=45.9$ months, range $=25-77$ months, VMA: $M=$ 17.3 , range $=9-48$ ). VMA of the participants at assessment was estimated from their level of expressive language, provided by file information and by language production during the ADOS-G according to the VMA equivalence from the Vineland scale level of expressive language (Sparrow, Balla, \& Cicchetti, 1984). From this list, a description of these behaviors was then constructed by grouping together similar descriptions and eliminating redundancy among items.

Three types of behaviors were listed at this stage: lateral glance (the child gazes laterally at an object, either while turning his head in the visual hemifield opposite to an object, or keeping his head straight while moving an object along his side); close gaze (the child inspects an object within a 3-inch range, either by leaning toward the object or bringing it close to his eyes); and obstructed gaze (the child inspects an object with a partially obstructed gaze, either by closing one eye, keeping both eyes half-closed, or by placing another object between himself and his object of interest). Three properties of objects associated with AVEBIOs were listed: movement, where the movement is induced by the child himself (e.g., moving his fingers in front of his eyes, spinning plates), or as a property of the object (e.g., ascending bubbles); elongation, vertical or horizontal axis resulting from the child's action (e.g., tower made of blocks) or a property of the object (edge of a table); and reflection (e.g., mirror, shining objects).

A second subsample of 8 children belonging to the same "biased" sample was scored using this coding system. Less frequent AVEBIOs types and object characteristics (less than 2 occurrences in the entire corpus) were discarded. Close gaze (2 occurrences), obstructed gaze ( 2 occurrences), elongation ( 0 occurrences), and reflection (0 occurrences) were therefore eliminated. ${ }^{1}$ Their frequency contrasted clearly with that of lateral glance (337 occurrences). The definition of the remaining item, lateral glance, is provided in Table 1 and exemplary images in Figure 1a and b.

\section{Reliability procedure}

The second step of coding system construction involved interrater reliability procedures using a Noldus Pro software. This software allows the scoring and timing of preestablished behaviors in digitized behavioral video-

1. One item, head cocking was frequently observed in the second sample. This item consisted of the child cocking his/her head to one side at the same height as or over an object, with the gaze directed toward the object. Although very reliable $(\mathrm{ICC}=.95)$ and very frequent (105 occurrences), because of the impossibility of reliably distinguishing this item from behavior present in typical children, the data on this behavior are not presented here. 
Table 1. Coding system (Study 1)

\begin{tabular}{ll}
\hline \hline AVEBIO & \multicolumn{1}{c}{ Description } \\
\hline Lateral glance & $\begin{array}{c}\text { Fixating on a target with the } \\
\text { pupils turned toward an } \\
\text { extreme corner of the eye } \\
\text { socket, where the head is } \\
\text { turned in the opposite direc- } \\
\text { tion of the target, in front of } \\
\text { it, or in the hemifield corre- } \\
\text { sponding to the target. (e.g., } \\
\text { inspection of a moving object } \\
\text { animated by the child himself } \\
\text { in the external part of the } \\
\text { visual hemifield). We do not } \\
\text { code functional lateral } \\
\text { glances, where the child looks } \\
\text { laterally toward a person, } \\
\text { when the lateral glance is } \\
\text { very fast (e.g., 1 s), followed } \\
\text { by a reorienting of the gaze } \\
\text { so that the object is fixed } \\
\text { centrally, or when the lateral } \\
\text { glance is within the context } \\
\text { of shaking the head "No." }\end{array}$ \\
\end{tabular}

tapes, according to different scorers. It provided a precise temporal tagging of each behavior, allowing frequency and duration computations of series of behaviors. To process a sufficiently large number of behaviors to check reliability, another set of 10 ADOS-G (8 boys, 2 girls; mean $\mathrm{CA}=45.7$, months $=25-67$; mean VMA $=15.5$, months $=9-30$ ) were scored by two scorers, G.M. and C.S.C. Videos were rated without speech. Intraclass correlation coefficients (ICCs) between the two scorers were all above .90 .

\section{Study 2: Frequency and Specificity of AVEBIOs Toward Typical Development}

The purpose of this second study was to establish the relative frequency/duration of the AVEBIO sampled in Study 1, lateral glance, in an unbiased sample of autistic children, that is, in a corpus of ADOS assessments that has not been selected on the basis of frequency of AVEBIOs. In addition, this study aimed to determine the specificity of this AVEBIO compared to typical development.

\section{Method}

Fifteen new ADOS-G videotapes were randomly chosen from the available sample of videotaped assessments. VMA (rather than nonverbal mental age [NVMA]) was used as a matching variable to maximize the delay of the autistic group. NVMA relies in part on autistic peaks of nonverbal ability (Mottron, 2004). Matching on NVMA might have resulted in a group quasiidentical to the CAmatched group. In contrast, the use of a comparison group much younger than the autistic group ensures that, in the case that a qualitative or quantitative difference in AVEBIOs is still found, this difference is not due to the developmental delay of the autistic group. Last, contrasted developmental levels (as assessed by VMA) were chosen to reveal a possible link between AVEBIOs and a specific developmental age. This resulted in a group (mean $\mathrm{CA}=44.5$ months, range $=33$ 73) composed of five nonverbal children ( VMA $=9$ months), two single word children (VMA $=14$ months), three two-word phrase children (VMA = 21 months), three threeword phrase children (VMA $=30$ months), and two verbally fluent children (VMA $=48$ months). Average ADOS scores were the following: module $1(n=10)$ : social + communication, $M=14.8, S D=3.7$; restricted interests and repetitive behaviors (RIRB), $M=$ 3.8, $S D=1.3$. Module $2(n=4)$ : social + communication, $M=11.0, S D=1.8$; RIRB, $M=2.5, S D=2.1 ;$ module $3(n=1)$ : social + communication, $M=5.0$; RIRB, $M=2.0$. Twelve of 15 participants were above the ADOS cutoff for autism. Two participants were between cutoffs for pervasive developmental disorder-not otherwise specified (PDD-NOS) and autism: one had a sociocommunicative score of 9 and an RIRB score of 2 and received a diagnosis of PDD-NOS; one had a sociocommunicative score of 10 and an RIRB score of 0 , and received a diagnosis of autism. One participant was under the cutoff for PDDNOS in social + communication area (5), had an RIRB score of 2, and received a clinical diagnosis of Asperger syndrome.

A comparison group composed of ADOS-G assessments of typically developing children 


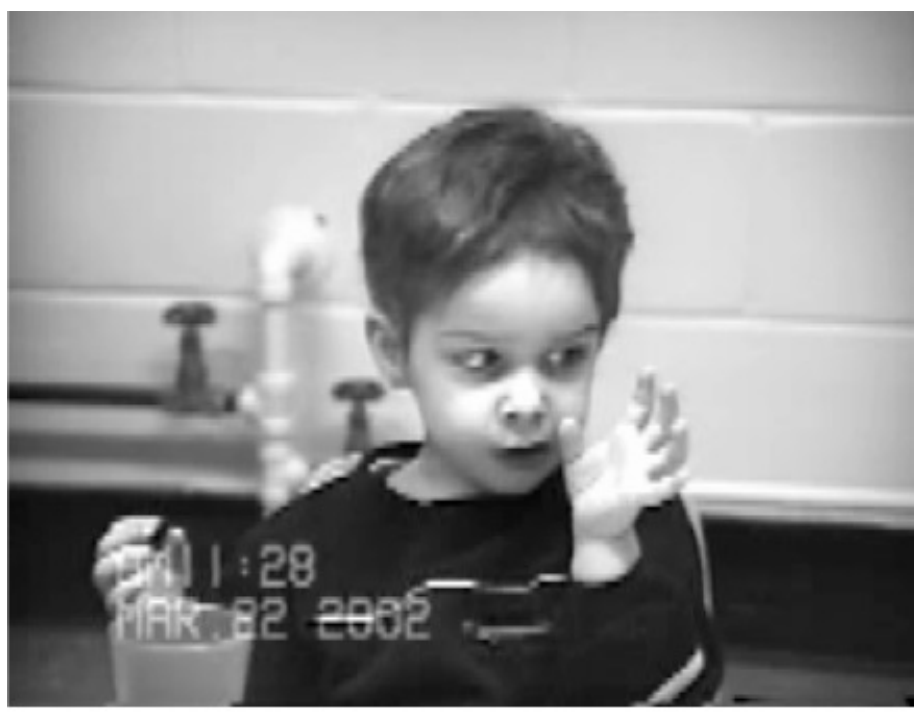

(a)

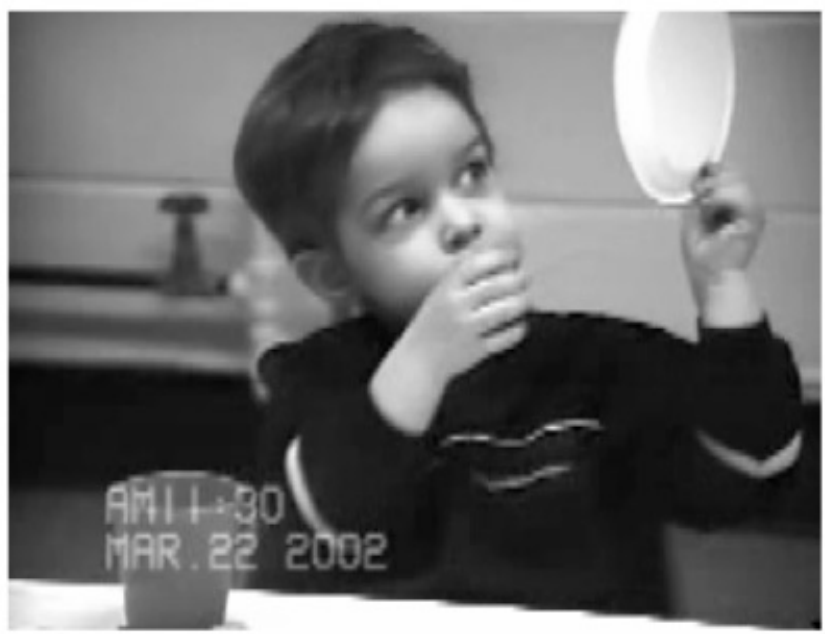

(b)

Figure 1. (a) Lateral glance and (b) movement and lateral glance.

performed or supervised by the same author (S.M.) was obtained, partially from a corpus of ADOS-G used for training purposes, partially from new ADOS-G assessments of children recruited by an announcement in the community. From this group of 13 participants, two overlapping comparison groups of 10 participants, one CA based and one VMA based, were formed (see Table 2).

Interrater reliability measures of lateral glance were also performed at this stage, and resulted in an ICC of .908 , for a total of 183 occurrences in 28 participants. To illustrate the interrater reliability and the frequency range of lateral glance in the clinical and the comparison group, individual scores according to the two raters are presented in Table 3. Finally, to compare the frequency of AVEBIOs on a consensual basis rather than a mere averaging of rater decisions, discrepancies between scorers were resolved using a best estimate procedure. Between-group comparisons and within-group 
Table 2. Chronological age and verbal mental age (months) of children with autism and comparison groups based on chronological age and based on verbal mental age (Study 2)

\begin{tabular}{|c|c|c|c|c|c|c|c|c|c|}
\hline \multirow[b]{3}{*}{ Age } & & & & \multicolumn{6}{|c|}{ Controls } \\
\hline & \multicolumn{3}{|c|}{ Autistics } & \multicolumn{3}{|c|}{ CA Based } & \multicolumn{3}{|c|}{ VMA Based } \\
\hline & $\begin{array}{c}M \\
(S D)\end{array}$ & Range & $\begin{array}{c}N \\
\mathrm{~B} / \mathrm{G}\end{array}$ & $\begin{array}{c}M \\
(S D)\end{array}$ & Range & $\begin{array}{c}N \\
\mathrm{~B} / \mathrm{G}\end{array}$ & $\begin{array}{c}M \\
(S D)\end{array}$ & Range & $\begin{array}{c}N \\
\mathrm{~B} / \mathrm{G}\end{array}$ \\
\hline $\mathrm{CA}$ & $\begin{array}{c}44.5 \\
(12.1)\end{array}$ & $33-73$ & $\begin{array}{c}15 \\
13: 2\end{array}$ & $\begin{array}{c}41.6 \\
(13.3)\end{array}$ & $24-68$ & $\begin{array}{c}10 \\
6: 4\end{array}$ & $\begin{array}{c}29.1 \\
(12.0)\end{array}$ & $\begin{array}{c}12-45 \\
5: 5\end{array}$ & 10 \\
\hline VMA & $\begin{array}{c}24.9 \\
(13.0)\end{array}$ & $12-48$ & 15 & \multicolumn{6}{|c|}{ VMA assumed identical to CA } \\
\hline
\end{tabular}

Note: CA, chronological age; VMA, verbal mental age; B/G, boys/girls.

Table 3. Individuals' scores of lateral glances according to the two raters in the clinical group (Study 2)

\begin{tabular}{crr}
\hline \hline & \multicolumn{2}{c}{ Lateral Gaze } \\
\cline { 2 - 3 } Autistics & CSC & GM \\
\hline 1 & 3 & 4 \\
2 & 0 & 2 \\
3 & 6 & 1 \\
4 & 0 & 1 \\
5 & 1 & 0 \\
6 & 1 & 4 \\
7 & 6 & 2 \\
8 & 0 & 2 \\
9 & 205 & 204 \\
10 & 293 & 249 \\
\hline \hline
\end{tabular}

Note: CSC and GM are raters.

correlations were then performed on the data resulting from this best estimate procedure.

\section{Results}

Average cumulative frequency and duration of lateral glances were computed per hour in the three groups (see Table 4). Lateral glances were considerably more frequent in the group of children with autism (around five times more than observed in both comparison groups). Average duration of lateral glances was significantly longer in the autistic group. No correlation between lateral glance and $\mathrm{CA}$, mental age (MA), or social + communication ADOS scores was evident.

\section{Study 3: Relation Between Lateral Glance and Properties of Objects}

The clinical impression related to lateral glances was that they occurred either in particular sequences (e.g., burst of lateral glances) or in particular contexts (e.g., staring laterally at a moving object). Additional sequential and contextual analyses were therefore conducted on the same sample of videotaped assessments used in Study 2.

First, a qualitative reexamination of the behavioral sequences containing lateral glances was performed. This revealed that in 12 of 15 autistic individuals (and 2 of the comparison group; Pearson $\chi^{2}=11.631(\mathrm{~b})$, asymptotic significance $[$ two sided $]=.001)$, lateral glances occur in "bursts," lasting $240 \mathrm{~s}$ or less (between 6 and $231 \mathrm{~s}$; containing on average 2-7 lateral glances). These bursts account for $76.7 \%$ of lateral glances.

Second, a series of analyses examined the visual context of lateral glances. To verify the clinical impression and indication in the literature that lateral glances were linked to move- 
Table 4. Average frequency and cumulative duration of lateral glances in clinical and comparison groups (Study 2)

\begin{tabular}{|c|c|c|c|c|c|c|}
\hline \multirow[b]{2}{*}{ Lateral Glance } & \multicolumn{2}{|c|}{$\begin{array}{l}\text { Autistics } \\
(n=15)\end{array}$} & \multicolumn{2}{|c|}{$\begin{array}{l}\text { CA Matched } \\
\text { Controls } \\
(n=10)\end{array}$} & \multicolumn{2}{|c|}{$\begin{array}{l}\text { VA Matched } \\
\text { Controls } \\
(n=10)\end{array}$} \\
\hline & $M$ & $S D$ & $M$ & $S D$ & $M$ & $S D$ \\
\hline \multicolumn{7}{|l|}{ Average cumulative } \\
\hline Frequency $(/ \mathrm{hr})$ & 11.97 & 9.5 & 2.15 & 3.2 & $2.52 \dagger$ & 3.3 \\
\hline Duration (/hr) & 13.46 & 13.8 & $3.64 * *$ & 6.6 & $4.36 * *$ & 6.4 \\
\hline
\end{tabular}

ment perception, we looked at any moving object in the visual field of lateral glances. In the autistic group, this resulted in $24.5 \%$ of lateral glances (39 of 159) occurring simultaneously with the perception of movement (comparison group: $3.4 \%$ of lateral glances, 1 of 29). Possible movements were: movement caused by the child, movement produced by another person, the relative movement of the child vis-à-vis a fixed object (e.g., bubbles followed by a whole body movement of the child rather than of just the gaze) or of the object relative to the child, or movement caused by the object itself. ${ }^{2}$ A particular situation was the temporal association of lateral glances and of movement, which occurred in 8 of 15 autistic participants (for a total of 24 associations) and two of the control group (for a total of 2 associations). This association was characterized by at least one lateral glance and one movement occurrence (between one and four) within a window of $30 \mathrm{~s}$ (although the 2 did not necessarily occur simultaneously). Movement occurrences $(47.3 \%, 44$ of 93$)$ were in this temporal relation with lateral glances (comparison group: $11.1 \%, 2$ of 18), suggesting a causal relation between the occurrence of the two behaviors in the autistic group.

2. An interrater reliability study on scoring of movement inspection (111 occurrences), that is, a prolonged glance toward a moving object, accompanied or not by positive emotions or mannerisms (e.g., "hand flapping"), was performed at this stage. This resulted in an ICC of .92 .

\section{General Discussion}

\section{Summary of findings}

This set of studies aimed to characterize atypical visual exploratory behaviors for inanimate objects in young children with autism. From these studies, we established that among atypical visual explorations observed in autistic children, one of them, lateral glance, was both more frequent than others among autistic children, and dramatically more frequent in autistic than in comparison children. This behavior can be reliably scored by trained scorers. It consists of staring at an object with the pupils in the corner of the eyes, while maintaining the head either in the direction of the object, straight ahead, or in a direction opposite to the object. In a significant number of cases the head is also inclined laterally during the visual inspection of an object. We also found that lateral glances are frequently associated with the presence of a moving object, either the child's own fingers, a manipulated object, or a surrounding moving object.

\section{Reliability issues}

Although the reliability reported here can be generalized only cautiously to other judges and to a larger population, the AVEBIO characterized in the current study, lateral glance, is detected with a high interrater reliability. This reliability has been conservatively obtained by scoring a posteriori ADOS-G direct assessments, which suggests that online scoring 
would have been still easier. This contrasts with the high difficulty to score and overall low frequency of stereotyped behaviors in general, and unusual sensory interests in particular, reported by Lord et al. during the ADOS-G specificity and reliability processes (Lord, Rutter, DiLavore, \& Risi, 2003). These authors concluded that the latter behaviors were "not useful classifying individuals in any of the modules." However, with respect to retrospective assessment (ADI-R), the current findings do not allow a determination of whether these behaviors may be reliably reported by parents or caregivers. In its current wording, which combines all types of atypical sensory behaviors in a single sentence, the specificity of the ADI-R item unusual sensory behaviors is high (>.90; Lord et al., 1997), but the sensitivity is low.

\section{Specificity of AVEBIOs toward typical and atypical development}

Although lateral glances are dramatically more prevalent in the autistic group, typically developing children present a small number of them and, for two children in our comparison group (1 and 3), the number of lateral glances was in the same range as that observed in the autistic group. A first developmental issue is to determine if lateral glances observed in the comparison group under study is caused by mechanisms similar to or different from those occurring in the autistic group. The first possibility, similarity of mechanism, would mean that the high occurrence of these behaviors in the autism group is due to the abnormal persistence of visual exploratory behaviors present in younger typically developing children (e.g., Tan, Salgado, \& Fahn, 1997). An alternative possibility is that the restricted numbers of lateral glances observed in the typically developing group are only superficially similar to those evident in the autistic group, and therefore, are linked to limitations of the specificity of the coding system in use here. Because of qualitative differences observed between behaviors apparently shared by the two populations, we favor this second interpretation. Accordingly, lateral glances observed in the two typically developing children exhibiting a large number of these behaviors were in the direction of a desired object remote from the child while he was solicited to do another item of the ADOS-G. In contrast, lateral glances unique to the autistic group were typically an inspection of a moving object animated by the child himself in the external part of the visual hemifield. Although this difference was detected a posteriori and therefore is not included in the current description of the behavior, it might be included in further version of the coding system to increase specificity.

Repetitive behaviors are frequently interpreted as resulting from developmental delays, as demonstrated by their increased frequency in various neurodevelopmental disorders associated with mental retardation (Wing \& Gould, 1979) and language delay (Cox et al., 1999; Michelotti, Charman, Slonims, \& Baird, 2002). In the current study, the frequency of lateral glances was greater in the autistic group than in the MA-matched group, which demonstrates that these behaviors cannot be interpreted merely as a reflection of a developmental delay. In the absence of a MA-matched comparison group with mental retardation, we cannot document the specificity of these behaviors toward other neurodevelopmental disorders. However, we contend that repetition is a trivial criterion for classifying behaviors (in the same way as a construct like "sensory dysfunction" is comprehensively uninformative about autistic perceptual and behavioral atypicalities, see Rogers \& Ozonoff, 2005), and that no statement regarding repetitive behaviors as a single entity should be enounced: a putative specificity of repetitive behaviors toward other neurodevelopmental conditions should be investigated separately for each individual behavior (e.g., lateral glance). For example, repetitive hand behaviors appear in both autism and Rett syndrome, but a further examination of hand movement in Rett syndrome has resulted in a finer grained description of this behavior, now included in the phenotype of this condition (Wales, Charman, \& Mount 2004). Similarly, the current study provides the preliminary finegrained characterization necessary to study the specificity of atypical visual behaviors to autism compared to other neurodevelopmental disorders. 


\section{Developmental Course of AVEBIOs}

In the current study, no correlations were found between the occurrence of lateral glances and VMA or CA; thus, there was no suggestion of an increase or a decrease of AVEBIOs with CA. The absence of correlation between lateral glances and social-communicative scores is consistent with the independence between repetitive symptoms and sociocommunicative symptoms found in several studies (e.g., Charman, 2003; Rogers et al., 2003). However, measuring correlations in these series of studies has several limitations. The small sample sizes produce low statistical power, and difficulty of verifying the normality of the distribution and the linearity of the relation among variables. Measuring VMA from Vineland language equivalent has a limited precision. In addition, using VMA as a measure of developmental age may underestimate developmental age in other areas more relevant to the behaviors under study. Last, the age range of our two groups is possibly too restricted to reveal a developmental trend.

Restricted interests and repetitive behaviors in general are reported to develop later (Charman et al., 2005; Fecteau, Mottron, Berthiaume, \& Burack, 2003) than sociocommunicative symptoms in autism, although repetitive use of objects is observed more frequently at 2 than at 9 years (Bishop, Huerta, Richler, Qiu, \& Lord, 2005). Charman and Baird (2002) and Cox et al. (1999) concluded that repetitive behaviors in general are more evident at the 4- to 5-year period than around 2 years of age, in agreement with most homemovie studies in which early impairments in social responses are emphasized. However, this conclusion may be dependent on the refinement of the coding system used to detect repetitive behaviors. For example, Militerni, Bravaccio, Falco, Fico, and Palermo (2002) were able to distinguish among simple, sensory-based repetitive behaviors and more complex ones, and found that the former were more frequent in very young children with autism.

The current findings of absence of correlation of lateral glances with MA or CA may lead to a reconsideration of the notion that all repetitive behaviors in autism appear after social-communicative symptoms. Consistent with this, Zwaigenbaum et al.'s (2005) recent prospective longitudinal study of children at risk for autism, using a new clinical rating scale, the Autism Observation Scale for Infants for scoring atypical behaviors in children under 1 year of age, found that longer fixation on objects could discriminate autistic from nonautistic children as early as 1 year of age. This result is consistent with that of Osterling, Dawson, and Munson (2002), who were able to use home videotapes of first birthday parties to distinguish children later diagnosed or not with autism on the basis of (among other positive and negative behaviors) stereotypic gestures.

\section{Contribution to neurocognitive models of atypical visual perception in autism}

The frequency of lateral glances, and association of lateral glances with moving objects, calls for an explanation. We propose that lateral glances may be related to the atypical perceptual processing capacities of autistic persons. At the developmental age where empirical investigations become possible, autistic individuals present with a local bias (spontaneous orientation for high spatial frequencies or for local level in the presence of compound visual information), a superior discrimination and detection of simple static visual information (Bertone et al., 2005, Deruelle et al., 2004; Lahaie et al., 2006; O'Riordan et al., 2001; Plaisted et al., 1998a, 1998b; see Mottron et al., 2006; Samson, Mottron, Jemel, Belin, \& Ciocca, 2006, for a review and an integrative model). Autistic adults also present a decreased capacity for processing integrative perceptual tasks such as second-order static and motion processing (Bertone et al., 2003, 2005; Blake, Turner, Smoski, Pozdol, \& Stone, 2003; see Brock, Brown, Boucher, \& Rippon, 2002; Milne et al., 2002; Dakin \& Frith, 2005, for a review). These findings have lead to the complexity processing $(\mathrm{CP})$ hypothesis (Bertone et al., 2003, 2005), which states that neurally defined "simple" perceptual processing is enhanced in autism, whereas more complex perceptual operations are impaired. In addition, 
superior discrimination of first order, static information represents a strong empirical basis for the hypothesis of a superior input of "local" visual information in natural settings, as stated by the enhanced perceptual functioning (EPF) model (Mottron et al., 2006). CP and EPF models contrast with the pathway specific hypothesis, which has been specifically developed to account for impaired movement processing. According to the pathway-specific model, the magnocellular pathway, that is, magnocellular layers of the lateral geniculate nuclei and their subsequent cortical, "dorsal" associated areas (Ungerleider \& Mishkin, 1982) would be selectively affected in autism (Blake et al., 2003; Milne et al., 2002, 2005). However, recent studies have questioned this interpretation. Bertone et al. $(2003,2005)$ demonstrated that similar types of deficits can be shown for motion (dorsal) and static form (ventral) stimuli when both stimuli required a network of several functional regions (V1 + V2/ $\mathrm{V} 3$; complex or second-order information) to be interpreted. However, when both motion and static form stimuli required only one functional region (V1; simple or first-order information) to be interpreted, the autistic observers performed at typical (dynamic information) or superior (static information) levels.

Whatever their neural underpinnings, these atypicalities observed in the adult autistic population offer a potential explanation for the lateral glances evident in autistic children in the present study. According to the EPF hypothesis, autistic individuals faced with this superior, and possibly uncomfortable or overwhelming, processing of low-level visual information would adopt behavioral strategies that regulate the amount of local information in an image or scene. This hypothesis is supported by what is known of transformation of visual information (from an observer's perspective) when eccentric viewing is used. Capacity to see visual information changes with eccentricity from the fovea, in the direction of logarithmic decrease of spatial information (Anstis, 1974). Eccentric viewing (as produced by lateral glance) produces a low-pass filtering of information, which removes details, leaving only the low spatial frequency information. Regarding movement percep- tion, which produces a temporal flickering, it is notable that the capacity to see temporal frequency information also changes with eccentricity (Faubert, 1991). In terms of frequency preference, temporal processing has a reverse trend from spatial information. Moving from central viewing decreases the capacity to see low temporal frequency information, while the capacity to see middle to high temporal frequency information remains more constant. Increasing eccentricity selectively filters temporal frequency information, and therefore simplifies the image seen for the cortex to interpret. For this reason, peripheral vision is often considered as being specialized for motion or flickering information. Eccentric viewing has an analogous effect on the processing of color information (Bilodeau \& Faubert, 1997, 1999), texture information (Anderson, Mullen, \& Hess, 1991), and symmetry (Labonte, Shapira, Cohen, \& Faubert, 1995).

It is therefore plausible that what an autistic observer does when fixating eccentrically is filtering the visual information to its simplest elements, flickering or moving stimuli, thereby regulating what he perceives in excess (high spatial frequencies) and optimizing what he otherwise perceives with difficulty (movement). According to this hypothesis, the local bias and EPF exhibited by adult autistics are consistent with an anomaly already present in infancy, which leads to regulatory behaviors with an impact on the processing of nonsocial as well as social information. According to this hypothesis, lateral glance in autism would result from a different mechanism from repetitive behaviors associated with other conditions, as those observed in fragile $\mathrm{X}$ syndrome. For example, Bertone et al. (2005) have demonstrated enhanced discrimination of first-order and diminished discrimination of second-order stimuli in autism, whereas persons with fragile $\mathrm{X}$ syndrome exhibit a different pattern, without enhanced perception of first-order stimuli (Kogan et al., 2004).

This hypothesis contrasts with current models of autism (e.g., Schultz, 2005), specifying that autistic atypicalities exist primarily as deficits in the processing of social material. A primary social deficit cannot easily account 
for, for example, the visual atypicalities found by Bertone et al. (2005) or the very early behaviors which plausibly serve to regulate these atypicalities in young autistic children. At a theoretical level, one condition for this hypothesis is that temporal/frequency variations in information perception with respect to eccentric viewing are the same in autistics and nonautistics; however, this has not been tested. The high-/low-frequency issue may also be only coincidental: an existing physical mechanism for filtering information would be used, because some type of filtration is needed, and not because of a "preference" for one or another type of filtered information. The spontaneous orientation toward the local aspect of compound information, consistently demonstrated in autistic adults in social and nonsocial information, on the one hand, and regulation of excessive amounts of high spatial frequency information on the other, may represent two aspects of the same phenomenon at different developmental age levels.

The current set of data and hypotheses may have relevant diagnostic, heuristic, and reha- bilitation consequences. At a diagnostic level, the reliability and specificity of AVEBIOs toward typical development, as well as their possible earlier occurrence than social manifestations of autism, make them plausible candidates as early behavioral markers of autism. At a heuristic level, the functional hypothesis raised above could be assessed by manipulating in empirical settings the dimensions of objects that possibly trigger lateral glances. We propose that these behaviors are due to a regulatory behavior where the autistic child orients his eyes and his head to produce a visual stimulation corresponding to the type of information that he processes the best and/or that suppresses discomfort or confusion. Therefore, it should be possible to demonstrate that these behaviors may be more often triggered by moving than by static objects and by high spatial frequencies than by low spatial frequencies. Last, and if supported by more empirical findings, the interpretation of some repetitive behaviors in autism as adaptive regulatory behaviors may question the effect of their suppression by rehabilitation programs on the person's well being.

\section{References}

Anderson, S. J., Mullen, K. T., \& Hess, R. F. (1991). Human peripheral spatial resolution for achromatic and chromatic stimuli: Limits imposed by optical and retinal factors. Journal of Physiology, 442, 47-64.

Anstis, S. M. (1974). Letter: A chart demonstrating variations in acuity with retinal position. Vision Research, 14, 589-592.

Baranek, G. T. (1999). Autism during infancy: A retrospective video analysis of sensory-motor and social behaviors at 9-12 months of age. Journal of Autism and Developmental Disorders, 29, 213-224.

Bertone, A., Mottron, L., Jelenic, P., \& Faubert, J. (2003). Motion perception in autism: A complex issue? Journal of Cognitive Neuroscience, 15, 218-225.

Bertone, A., Mottron, L., Jelenic, P., \& Faubert, J. (2005). Enhanced and diminished visuo-spatial information processing in autism depends on stimulus complexity. Brain, 128, 2430-2441.

Bilodeau, L., \& Faubert, J. (1997). Isoluminance and chromatic motion perception throughout the visual field. Vision Research, 37, 2073-2081.

Bilodeau, L., \& Faubert, J. (1999). The oblique effect with colour defined motion throughout the visual field. Vision Research, 39, 757-763.

Bishop, S., Huerta, M., Richler, J., Qiu, S., \& Lord, C. (2005). Developmental course of restricted and repetitive behaviors in children with autism spectrum disorders. Paper presented at the IMFAR conference, Boston, May 2005.
Blake, R., Turner, L. M., Smoski, M. J., Pozdol, S. L., \& Stone, W. L. (2003). Visual recognition of biological motion is impaired in children with autism. Psychological Science, 14, 151-157.

Boeschoten, M., Kemner, C., Kenemans, L., \& Engeland, $\mathrm{H}$. V. (2005). Face processing in children with pervasive developmental disorder: The roles of expertise and spatial frequency. Poster presented at the IMFAR conference, Boston, May 2005.

Brock, J., Brown, C. C., Boucher, J., \& Rippon, G. (2002). The temporal binding deficit hypothesis of autism. Development and Psychopathology, 14, 209-224.

Charman, T., \& Baird, G. (2002). Practitioner review: Diagnosis of autism spectrum disorder in 2- and 3-yearold children. Journal of Child Psychology and Psychiatry, 43, 289-305.

Charman, T. (2003). Why is joint attention a pivotal skill in autism? Philosophical Transactions of the Royal Society, 358, 315-324.

Charman, T., Taylor, E., Drew, A., Cockerill, H., Brown, J., \& Baird, G. (2005). Outcome at 7 years of children diagnosed with autism at age 2: Predictive validity of assessments conducted at 2 and 3 years of age and pattern of symptom change over time. Journal of Child Psychology and Psychiatry, 46, 500-513.

Chawarska, K., Klin, A., \& Volkmar, F. (2003). Automatic attention cueing through eye movement in 2 -year-old children with autism. Child Development, $74,1108-1122$. 
Colman, R. S., Frankel, F., Ritvo, E., \& Freeman, B. J. (1976). The effects of fluorescent and incandescent illumination upon repetitive behaviors in autistic children. Journal of Autism and Child Schizophrenia, 6 , 157-162.

Cox, A., Klein, K., Charman, T., Baird, G., Baron-Cohen, S., Swettenham, J., et al. (1999). Autism spectrum disorders at 20 and 42 months of age: Stability of clinical and ADI-R diagnosis. Journal of Child Psychology and Psychiatry, 40, 719-732.

Dakin, S., \& Frith, U. (2005). Vagaries of visual perception in autism. Neuron, 48, 497-507.

Dawson, G., Webb, S. J., \& McPartland, J. (2005). Understanding the nature of face processing impairment in autism: Insights from behavioral and electrophysiological studies. Developmental Neuropsychology, 27, 403-424.

Deruelle, C., Rondan, C., Gepner, B., \& Tardif, C. (2004). Spatial frequency and face processing in children with autism and Asperger syndrome. Journal of Autism and Developmental Disorders, 34, 199-210.

Dunn, W. (1999). The sensory profile examiner's manual. San Antonio, TX: The Psychological Corporation.

Faubert, J. (1991). Effect of target size, temporal frequency and luminance on temporal modulation visual fields. In R. P. Mills \& A. Heijl (Eds.), Perimetry update 1990/1991 (pp. 381-390). Amsterdam: Kugler.

Fecteau, S., Mottron, L., Berthiaume, C., \& Burack, J. A. (2003). Developmental changes of autistic symptoms. Autism, 7, 255-268.

Filipek, P. A., Accardo, P. J., Baranek, G. T., Cook, E. H., Jr., Dawson, G., Gordon, B., et al. (1999). The screening and diagnosis of autistic spectrum disorders. Journal of Autism and Developmental Disorders, 29, 439-484.

Frankel, F., Freeman, B. J., Ritvo, E., Chikami, B., \& Carr, E. (1976). Effects of frequency of photic stimulation upon autistic and retarded children. American Journal of Mental Deficiency, 81, 32-40.

Freeman, B. J., Ritvo, E. R., Yokota, A., \& Ritvo, A. (1986). A scale for rating symptoms of patients with the syndrome of autism in real life settings. Journal of American Academy of Child Psychiatry, 25, 130-136.

Frith, C. (2003). What do imaging studies tell us about the neural basis of autism? In G. Bock \& J. Goode (Eds.), Novartis Foundation Symposium: Vol. 251. Autism: Neural basis and treatment possibilities (pp. 149-166, 166-176, 281-297). Chichester: Wiley.

Kanner, L. (1943). Autistic disturbances of affective contact. The Nervous Child, 2, 217-250.

Kogan, C. S., Bertone, A., Cornish, K., Boutet, I., DerKaloustian, V. M., Andermann, E., et al. (2004). Integrative cortical dysfunction and pervasive motion perception deficit in fragile X syndrome. Neurology, $63,1634-1639$.

Labonte, F., Shapira, Y., Cohen, P., \& Faubert, J. (1995). A model for global symmetry detection in dense images. Spatial Vision, 9, 33-55.

Lahaie, A., Mottron, L., Arguin, M., Berthiaume, C., Jemel, B., \& Saumier, D. (2006). Face perception in high-functioning autistic adults: Evidence for superior processing of face parts, not for a configural face processing deficit. Neuropsychology, 20, 30-41.

Lord, C. (1995). Follow-up of two-year-olds referred for possible autism. Journal of Child Psychology and Psychiatry, 36, 1365-1382.

Lord, C., Pickles, A., McLennan, J., Rutter, M., Bregman, J., Folstein, S., et al. (1997). Diagnosing autism: Analy- ses of data from the Autism Diagnostic Interview. Journal of Autism and Developmental Disorders, 27, 501-517.

Lord, C., Risi, S., Lambrecht, L., Cook, E. H., Jr., Leventhal, B. L., DiLavore, P. C., et al. (2000). The autism diagnostic observation schedule-generic: A standard measure of social and communication deficits associated with the spectrum of autism. Journal of Autism and Developmental Disorders, 30 , 205-223.

Lord, C., Rutter, M., DiLavore, P., \& Risi, S. (2003). Autism diagnostic observation schedule. ADOS manual. Los Angeles: Western Psychological Services.

Lord, C., Rutter, M., \& Le Couteur, A. (1994). Autism Diagnostic Interview-Revised: A revised version of a diagnostic interview for caregivers of individuals with possible pervasive developmental disorders. Journal of Autism and Developmental Disorders, 24, 659-685.

Lord, C., Storoschuck, S., Rutter, M., \& Pickles, A. (1993). Using the ADI-R to diagnose autism in preschool children. Infant Mental Health Journal, 14, 235-252.

Michelotti, J., Charman, T., Slonims, V., \& Baird, G. (2002). Follow-up of children with language delay and features of autism from the pre-school years into middle childhood. Developmental Medicine and Child Neurology, 44, 812-819.

Militerni, R., Bravaccio, C., Falco, C., Fico, C., \& Palermo, M. T. (2002). Repetitive behaviors in autistic disorder. European Child and Adolescent Psychiatry, $11,210-218$

Milne, E., Swettenham, J., \& Campbell, R. (2005). Motion perception and autistic spectrum disorder: A review. Current Psychology of Cognition, 23, 3-36.

Milne, E., Swettenham, J., Hansen, P., Campbell, R., Jeffries, H., \& Plaisted, K. (2002). High motion coherence thresholds in children with autism. Journal of Child Psychology and Psychiatry, 43, 255-263.

Minshew, N. J., Goldstein, G., \& Siegel, D. J. (1997). Neuropsychologic functioning in autism: Profile of a complex information processing disorder. Journal of the International Neuropsychological Society, 3, 303-316.

Mottron, L. (2004). Matching strategies in cognitive research with individuals with high-functioning autism: Current practices, instrument biases, and recommendations. Journal of Autism and Developmental Disorders, 34, 19-27.

Mottron, L., Burack, J. A., Iarocci, G., Belleville, S., \& Enns, J. (2003). Locally oriented perception with intact global processing among adolescents with high functioning autism: Evidence from Multiple Paradigms Journal of Child Psychology and Psychiatry, 44, 906-913.

Mottron, L., Dawson, M., Soulières, I., Hubert, B., \& Burack, J. A. (2006). Enhanced perceptual functioning in autism: An updated model, and eight principle of autistic perception. Journal of Autism and Developmental Disorders, 36, 27-43.

O’Neill, M., \& Jones, R. S. (1997). Sensory-perceptual abnormalities in autism: A case for more research? Journal of Autism and Developmental Disorders, 27, 283-293.

O'Riordan, M. A., Plaisted, K. C., Driver, J., \& BaronCohen, S. (2001). Superior visual search in autism. Journal of Experimental Psychology: Human Perception and Performance, 27, 719-730.

Osterling, J. A., Dawson, G., \& Munson, J. A. (2002). Early recognition of 1 -year-old infants with autism 
spectrum disorder versus mental retardation. Development and Psychopathology, 14, 239-251.

Pellicano, E., Gibson, L., Maybery, M., Durkin, K., \& Badcock, D. R. (2005). Abnormal global processing along the dorsal visual pathway in autism: A possible mechanism for weak visuospatial coherence? Neuropsychologia, 43, 1044-1053.

Plaisted, K. (2001). Reduced generalization in autism: An alternative to weak central coherence. In J. A. Burack, T. Charman, N. Yirmiya, \& P. R. Zelazo (Eds.), The development of autism: Perspectives from theory and research (pp. 149-169). Mahwah, NJ: Erlbaum.

Plaisted, K., O'Riordan, M., \& Baron-Cohen, S. (1998a). Enhanced discrimination of novel, highly similar stimuli by adults with autism during a perceptual learning task. Journal of Child Psychology and Psychiatry, 39, $765-775$.

Plaisted, K., O'Riordan, M., \& Baron-Cohen, S. (1998b). Enhanced visual search for a conjunctive target in autism: A research note. Journal of Child Psychology and Psychiatry, 39, 777-783.

Ritvo, E. R., Creel, D., Crandall, A. S., Freeman, B. J., Pingree, C., Barr, R., et al. (1986). Retinal pathology in autistic children-A possible biological marker for a subtype? Journal of American Academy of Child Psychiatry, 25, 137.

Ritvo, E. R., \& Laxer, G. (1983). Autisme: La vérité refuse. In Handicaps et réadaptation (pp. 70-71). Paris: SIMEP SA.

Ritvo, E. R., Ornitz, E. M., Eviatar, A., Markham, C. H., Brown, M. B., \& Mason, A. (1969). Decreased postrotatory nystagmus in early infantile autism. Neurology, 19, 653-658.

Ritvo, E. R., Ornitz, E. M., \& La Fanchi, S. (1968). Frequency of repetitive behaviors in early infantile autism and its variants. Archives of General Psychiatry, 19, 341-347.

Rogers, S. J., Hepburn, S., \& Wehner, E. (2003). Parent reports of sensory symptoms in toddlers with autism and those with other developmental disorders. Journal of Autism and Developmental Disorders, 33, 631-642.

Rogers, S. J., \& Ozonoff, S. (2005). Annotation: What do we know about sensory dysfunction in autism? A critical review of the empirical evidence. Journal of Child Psychology and Psychiatry, 46, 1255-1268.
Samson, F., Mottron, L., Jemel, B., Belin, P., \& Ciocca, V. (2006). Can spectro-temporal complexity explain the autistic pattern of performance on auditory tasks? Journal of Autism and Developmental Disorders, 36, 65-76.

Schultz, R. T. (2005). Developmental deficits in social perception in autism: The role of the amygdala and fusiform face area. International Journal of Developmental Neuroscience, 23, 125-141.

Shah, A., \& Frith, U. (1983). An islet of ability in autistic children: A research note. Journal of Child Psychology and Psychiatry, 24, 613-620.

Shah, A., \& Frith, U. (1993). Why do autistic individuals show superior performance on the block design task? Journal of Child Psychology and Psychiatry, 34, 1351-1364.

Sigman, M., Dijamco, A., Gratier, M., \& Rozga, A. (2004). Early detection of core deficits in autism. Mental Retardation and Developmental Disabilities Research Review, 10, 221-233.

Sparrow, S. S., Balla, D., \& Cicchetti, V. (1984). Vineland adaptative behavior scales. Circle Pines, MN: American Guidance Service.

Tan, A., Salgado, M., \& Fahn, S. (1997). The characterization and outcome of stereotypical movements in nonautistic children. Movement Disorders, 12, 47-52.

Ungerleider, L. G., \& Mishkin, M. (1982). Two cortical visual systems. In D. J. Ingle, M. A. Goodale, \& R. J. W. Mansfield (Eds.), Analysis of visual behavior (pp. 549586). Cambridge, MA: Massachusetts Institute of Technology.

Wales, L., Charman, T., \& Mount, R.H. (2004). An analogue assessment of repetitive hand behaviors in girls and young women with Rett syndrome. Journal of Intellectual Disabilities Research, 48, 672-678.

Wing, L., \& Gould, J. (1979). Severe impairments of social interaction and associated abnormalities in children: Epidemiology and classification. Journal of Autism and Developmental Disorders, 9, 11-29.

Zwaigenbaum, L., Bryson, S., Rogers, T., Roberts, W., Brian, J., \& Szatmari, P. (2005). Behavioral manifestations of autism in the first year of life. International Journal of Developmental Neuroscience, 23, 143 152. 